\title{
USAGE AND PERCEPTION OF GEOFENCING
}

\author{
Dr.V.Suganya \\ Research Centre of Commerce, Fatima College, Madurai
}

Article DOI: $\frac{\text { https://doi.org/10.36713/epra9463 }}{\text { DOI No: } 10.36713 / \text { epra9463 }}$

Geofencing is a location-based service in which an app or other software uses GPS, RFID, Wi-Fi or cellular data to trigger a pre-programmed action when a mobile device or RFID tag enters or exits a virtual boundary set up around a geographical location, known as a geofence. Depending on how a geofence is configured it can prompt mobile push notifications, trigger text messages or alerts, send targeted advertisements on social media, allow tracking on vehicle fleets, disable certain technology or deliver location-based marketing data.

\section{GEOFENCING APPLICATIONS}

With the rising popularity of mobile devices, geofencing has become a standard practice for plenty of businesses. Once a geographic area has been defined, the opportunities are seemingly endless for what companies can do, and it has become especially popular in marketing and social media.

Some retail and hospitality businesses will set up geofences around their competition, so when you approach the boundary, you'll get a push notification prompting you to visit the other establishment. Or, you might walk into a retail store and see a coupon pushed to your device. If you download a grocery app, chances are it will register when you drive by to prompt an alert, trying to get you to stop in.

Here are other common geofencing applications:

- Social networking: One of the most recognizable uses for geofencing comes in the form of popular social networking apps - most notably, Snapchat. Location-based filters, stickers and other shareable content are all made possible with geofencing. Whether you're using a promoted filter at a concert, using a custom-made filter for a friend's birthday or uploading to public, location-based stories, it's all thanks to these virtual perimeters.

- Marketing: Besides social networking, geofencing is also a popular way for businesses to deliver instore promotions, alerting you right as you step in range of the store. Geofencing also helps businesses target ads to a specific audience to figure out what strategies work best based off user's location-data.

- Audience engagement: Geofencing is used to engage crowds of people at organized events, like concerts, festivals, fairs and more. For example, a concert venue might use a geofence to crowdsource social media posts or deliver information about the venue or event.

- Smart appliances: As more of our appliances get "smart," with Bluetooth capabilities, it's easier than ever to program your fridge to remind you that you're out of milk the next time you pass by the grocery store. Or you can make sure the thermostat is set to the perfect temperature when you get home from work by using a geofence.

- Human resources: Some companies rely on geofencing for monitoring employees, especially workers who spend time off-site doing field work. It's also an easy way to automate time cards, clocking employees in and out as they come and go.

- Telematics: Geofencing can also be helpful with telematics, allowing companies to draw virtual zones around sites, work areas and secure areas. They can be triggered by a vehicle or a person and send alerts or warnings to the operator.

- Security: Geofencing might seem invasive - and it certainly has the potential to sometimes feel like an overreach depending on how it's used. However, geofencing can also be used to bring more security to your mobile device. For example, you can set your phone to unlock when you're home using a geofence or to get alerts when someone enters the house or leaves. 


\section{MAIN BENEFITS OF GEOFENCING}

What is it about geofencing that gets marketer's excited and how can it help your marketing efforts? Here are the major benefits:

\section{Better Targeting}

With the ability to hyper-target prospects you'll not only be able to reach folks at the right time and at the right place but be able to engage them with messaging that is relevant and timely. By targeting folks in a specific geographic area, and filtering that area by specific targeting criteria, you're much more likely to engage your prospects. Using the Sephora example above: a marketer would not send out the "lipstick" messaging to any Jane, Dick or Harry that walked by, rather would have targeted that ad to a specific demographic.

\section{Spend Effectiveness}

When your advertising is hyper-targeted, and sent at the right time and right place, your engagement numbers go up. With geofencing, you're spending marketing dollars on prospects that are most likely to take action, and spending less money on those that are not.

\section{Improved Data Collection}

Once geofencing is implemented you'll get access to a ton of insightful data metrics such as insights on which brick and mortars are performing better, which target segment has higher engagement, traffic patterns (when people are in/near your locations), stay durations, and messaging effectiveness. By combining this collected information with online activity, purchase information and web browsing behaviors a business can improve the user experience, increase engagement, and better understand user behavior. This same information can also be used to target folks who have previously visited certain locations, to create customized follow-up messaging.

\section{Personalized Customer Experience}

Geofencing also allows you to personalize the customer experience. If you're marketing to a specific area, you can utilize the demographics of that local population and customize your promotions accordingly. For example, if a popular, local high school basketball team is doing really well this year, you could utilize that information to create some customized promotions

\section{Competitive Advantage}

When thinking about where to put your virtual fence, consider not just your own physical location, but where are your customers likely to be? It may not always be where you are.

Utilizing this tactic has proven hugely successful for many big brands. Why? Because geofencing provides the ability to draw prospects away from the competition. Back in 2016, Dunkin Donuts famously utilized geofencing technology to lure customers away from the competition by creating geofences around other coffee shops in the area and sending targeted ads to those prospects. Of the 36 percent that clicked on the offer (a coupon), 18 percent saved the coupon and 3.6 percent returned to redeem their coupon. Geofence virtual barriers can be active or passive. Active geofences require an end user to opt-in to location services and a mobile app to be open. Passive geofences are always on; they rely on Wi-Fi and cellular data instead of GPS or RFID and work in the background.

The technology has many practical uses, including:

\begin{tabular}{|l|l|}
\hline \multicolumn{1}{|c|}{ Use } & \multicolumn{1}{|c|}{ Example } \\
\hline Drone management & $\begin{array}{l}\text { A sporting event can use geo-fencing to create a temporary no-fly zone that prevents drones from } \\
\text { crossing a defined perimeter. }\end{array}$ \\
\hline Fleet management & Geo-fencing can alert a dispatcher when a truck driver breaks from his route. \\
\hline $\begin{array}{l}\text { Human resource } \\
\text { management }\end{array}$ & $\begin{array}{l}\text { An employee's smart card will send an alert to security if the employee attempts to enter an } \\
\text { unauthorized, geo-fenced area. }\end{array}$ \\
\hline $\begin{array}{l}\text { Compliance } \\
\text { management }\end{array}$ & $\begin{array}{l}\text { Network logs can record geo-fence crossings to document the proper use of devices and } \\
\text { their compliance with established policies. }\end{array}$ \\
\hline Marketing & $\begin{array}{l}\text { A small business can text an opt-in customer a coupon code when the customer's smartphone enters a } \\
\text { defined geographical area. }\end{array}$ \\
\hline Asset management & $\begin{array}{l}\text { A network administrator can set up alerts so when a hospital-owned iPad leaves the hospital grounds, the } \\
\text { administrator can monitor the device's location and lock it down to prevent it from being used. }\end{array}$ \\
\hline Law enforcement & An ankle bracelet can alert authorities if an individual under house arrest leaves the premises. \\
\hline Home automation & $\begin{array}{l}\text { When the home owner's smartphone leaves the home's geo-fenced perimeter, the thermostat lowers itself } \\
\text { to a pre-defined temperature. }\end{array}$ \\
\hline
\end{tabular}




\section{DIFFERENT USES \& APPLICATIONS OF GEOFENCING}

- Marketing Your Business - As mentioned above, businesses and enterprises can use geofencing as a marketing tool to serve ads to people across 100,000's of mobile apps and websites after that individual walked inside the geofenced location and even see the ads long after they left the geofenced location (30 days or longer). It can also be used to trigger alerts by retailers to people who downloaded the retailers app and that individual walked nearby or inside the geofenced location set up by the retailer.

- Asset Management - Owners of assets can install geofencing technology into their assets (cards, truck, tractors, computers, etc..) to track when those assets are taken outside of a geofenced location.

- Fleet Management - Many trucking and fleet based companies are using geofencing to track their vehicles based on where they're going. The HERE Fleet Telematics Geofencing is a REST API that allows you to track whether or not mobile assets are located within the specified geographic areas. An asset is any kind of trackable object, such as a person, car, smartphone, or delivery package.

- Human Resource Management - Companies such as Quickbooks and other software companies are beginning to incorporate geofencing technology into their solutions to allow employees to not only track their time, but to determine if someone has truly left a geofenced location after clocking out.

- Drone Management - Drones are becoming a big deal with delivery but also for taking imagery, videos and more. RFID's and GPS tracking for the use of geofencing allow drones to be pinpointed on maps. And the use of drones can be better managed when a geofence is drawn thus ensuring that drone doesn't leave the said geofenced area.

- Law Enforcement - Law enforcement is using geofencing to track people who may have committed a crime. It does require law enforcement to issue a warrant to a judge. These warrants compel a technology company (so far, only Google) to disclose anonymized location records for any devices in a certain area during a specified time period.. Some say this is in violation of the 4th amendment, but the area is still grey for now.

- $\quad$ Tracking Spouses - We are seeing people who may not fully trust their spouse implement geofencing by placing and installing tracking technology on their spouses smart phones and even vehicle to track their location and their physical behavior.

- Tracking Animals - A number of pet owners are also using geofencing to track animals such as dogs, cats, cattle, and such. Those pet owners will place a geofence around a particular boundary and when the pet wanders outside of that boundary, an alert or trigger is set off to ensure the owner to quickly locate and find the animal. Also, pet owners use it to slightly shock the animal to change their behavior and ensure the pet doesn't leave a particular boundary.

- Security Geofencing - Similar to animal tracking, security companies are deploying geofencing technology in the security space. This is available on modern, high-tech smart home security systems, and set up is very easy. Using the system's free, compatible app, you can choose a location, distance, and variety of actions. The distance and location work together to define a perimeter, or fence, around a set point. Then, the app constantly monitors your location.

$\begin{array}{cl}\circ & \text { Lighting (via Smart Outlets or Bub } \\ \circ & \text { Thermostats } \\ \circ & \text { Door Locks } \\ \circ & \text { Alarm Arming System } \\ \circ & \text { Television } \\ \circ & \text { Appliances } \\ \circ & \text { Lawn Speaker Systems } \\ \circ & \text { Garage Door Openers } \\ \circ & \text { Water Shut Offs } \\ \circ & \text { GPS Trackers (Great for kids!) } \\ \circ & \text { Sound Systems }\end{array}$

- Market Research - Geofencing technology can also be use for market research purposes and to determine where people are going and the types of people based on demographic and psychographic data where they are frequenting.

\section{THE FUTURE OF GEOFENCING}

There are some cautions with geofencing, especially when it comes to privacy with marketing. Just this past year, Massachusetts was one of the first states to enact a consumer protection law that objected to the use of location-based advertising. The Attorney General blocked an ad campaign from Copley Advertising, which was hired by a Christian organization to set up a geofence around women's health clinics that would target 
women in the waiting room or nearby with anti-abortion ads. However, despite questions about security, it doesn't seem that geofencing will lose its popularity any time soon. According to a press release from MarketsandMarkets, the geofencing industry is expected to grow over 27 percent by 2022, citing "technological advancements in use of spatial data and increasing applications in numerous industry verticals."

\section{REVIEW OF LITERATURE}

Akira Suyama \& Ushio Inoue (2016) made a study in Tokeyo on "Using Geofencing for a Disaster Information System". It proposes a disaster information system using the geofencing technology $\square$ to detect the movement of users and provide information of the risk for them. The system is composed of client-server architecture; the server collects risk information from various information sources and the client watches the user to notify the information as the need arises. To detect the user's movement, the client creates a virtual fence called geofence at the dangerous area based on the risk information stored in the server, and monitors the user's entry and exit of the fence. Thus the system can deliver warnings and advices timely to specific users in danger. The location of the user was detected with high accuracy when entering the fence, but the accuracy was low when exiting the fence.

Akira Suyama \& Ushio Inoue (2016) “Using Geofencing for a Disaster Information System" 978-1-50900806-3/16/\$31.00 copyright 2016 IEEE ICIS 2016, June 26-29, 2016, Okayama, Japan

Application of Geofencing Technology for the Purpose of Spatial Analyses in Inland Mobile Navigation

- June 2016

DOI:10.1109/BGC.Geomatics.2016.15

- Conference: 2016 BALTIC GEODETIC CONGRESS (BGC GEOMATICS)

Natalia Wawrzyniak \& Tomasz Hyla (2016) made study in Szczecin on Application of Geofencing Technology for the Purpose of Spatial Analyses in Inland Mobile Navigation" . In this paper it was analyzed geofencing technology in inland mobile navigation systems. It described implementation issues related to proximity analysis used for safety and informational purposes with the usage of geofences. This includes generation of warnings and alarm messages when approaching to navigational hazards. Characteristics of spatial data management in mobile on-water navigation systems are presented. Advantages and disadvantages of applying geofencing technology in spatial analyses are described.

Natalia Wawrzyniak \& Tomasz Hyla (2016) "Application of Geofencing Technology for the Purpose of Spatial Analyses in Inland Mobile Navigation”. DOI:10.1109/BGC.Geomatics.2016.15

- $\quad$ Conference: 2016 BALTIC GEODETIC CONGRESS (BGC GEOMATICS)

https://www.cio.com/article/288810/geofencing-explained.html

https://www.plotprojects.com/blog/what-is-geofencing/

https://www.computerworld.com/article/3528795/geofencing-what-is-it.html 